\title{
Análise das mudanças do uso e da cobertura da terra em municípios com áreas de mineração na microrregião de Itabira, a partir de dados do MAPBIOMAS entre 1987 e 2017
}

Rafael Adighieri Moraes ${ }^{1}$

\begin{abstract}
RESUMO
Atualmente, a análise da dinâmica do uso do espaço é de extrema importância em estudos de planejamento e monitoramento da ação humana. Estes estudos permitem diagnósticos sobre o crescimento econômico e social sustentável. Nesse contexto, este trabalho teve por objetivo identificar se houve mudanças no uso da terra em municípios com áreas de mineração na microrregião de Itabira, que possam ter gerado desenvolvimento além ou devido à mineração. Foram utilizadas imagens do MAPBIOMAS para geração de mapas de uso da terra, para os anos de 1987, 1997, 2007 e 2017, além de gráficos e matrizes de transição de modo a permitir uma análise de 30 anos. Os resultados indicaram que houve poucas mudanças expressivas. As principais mudanças, em geral, foram o crescimento da infraestrutura urbana e de áreas de mineração. Identificou-se também diminuição da floresta nativa e aumento de áreas com floresta plantada, provavelmente eucalipto. Porém, alguns municípios áreas de pastagens foram substituídas por mata nativa e mosaico de agricultura e pecuária, indicando desenvolvimento e recuperação ambiental.
\end{abstract}

Palavras-chave: Geoprocessamento. Mineração. Desenvolvimento.

\footnotetext{
${ }^{1}$ Graduado em Engenharia Agrícola pela Universidade Federal de Lavras - UFLA. Mestre em Meteorologia Agrícola pela Universidade Federal de Viçosa - UFV e Doutor em Engenharia Agrícola pela Universidade Estadual de Campinas - UNICAMP. Atualmente é pesquisador e professor da Universidade do Estado de Minas Gerais - UEMG, Unidade João Monlevade, MG, Brasil. E-mail: rafagricola@yahoo.com.br.
} 


\title{
Analysis of changes in land use and land cover in municipalities with mining areas in the Itabira microregion, using data from MAPBIOMAS between 1987 and 2017
}

\begin{abstract}
Currently, the analysis of the dynamics of the use of geographical space is extremely important in studies of planning and monitoring of human action. These studies allow diagnoses about sustainable economic and social growth. In this context, the work aimed to identify whether there were changes in land use in the Itabira microregion that may have generated development beyond or due the mining. MAPBIOMAS images were used for the generation of land use maps for the years 1987, 1997, 2007 and 2017, in addition to graphs and transition matrices in order to allow a 30-year analysis of land cover use. It was observed that there were few significant changes. The main changes, in general, were the growth of urban infrastructure and mining areas. It was also identified as a decrease in the native forest (forest formation) and an increase in areas with planted forest, probably eucalyptus. However, some municipalities with pasture areas have been replaced by native forest and mosaic of agriculture and livestock, indicating development and environmental recovery.
\end{abstract}

Keywords: Geoprocessing. Mining. Development.

Artigo recebido em: 22/06/2020

Aceito em: 04/12/2020 


\section{INTRODUÇÃO}

Atualmente, a análise da dinâmica do uso do espaço geográfico (favorecido pela tecnologia disponível) é de extrema importância em estudos de planejamento e monitoramento da ação humana. Estes estudos permitem diagnósticos sobre o crescimento econômico e social sustentável, além da identificação de novas áreas de mineração, crescimento das áreas urbanas, desmatamento, agricultura, erosão, assoreamento de rios, mata ciliar, pastagens, etc. Segundo BRAGA (2007) a ação humana na Terra e suas contradições possuem uma implicação espacial e temporal, pois denotam produção de espaço que varia no tempo.

Para o setor público, o conhecimento da dinâmica do uso da terra, permite ações mais efetivas, tanto para melhorar a qualidade de vida dos habitantes, como identificação de desmatamentos, áreas propícias a incêndios, poluição, crescimento da zona urbana e classificação do foco de produção na zona rural. Permite também análises de impactos econômicos e sociais ocasionados pela inclusão ou exclusão de empresas ao longo do tempo (mineradoras por exemplo).

Para o setor privado, informações de uso do espaço geográfico, contribuem para planejamento de novos investimentos e identificação de áreas potenciais em cada município, favorecendo a economia e a empregabilidade. $\mathrm{O}$ setor mineral gera resultados positivos no campo econômico que podem ser dimensionados pela produção e comercialização dos bens minerais, pela oferta de empregos e pela geração de receitas tributárias, taxas e royalties (NAHAS et al., 2019).

A microrregião de Itabira, possui relevo acidentado e biomas entre mata atlântica e cerrado. A dificuldade de acesso aos locais, devido ao relevo acidentado, favorece o uso de tecnologias de sensoriamento remoto, permitindo ações mais efetivas na identificação de problemas. Além disso, áreas com alta declividade, dependendo do tipo de solo e vegetação, ao sofrerem alterações na cobertura (desmatamento), são propícias à erosão, causando não apenas perda de solo como assoreamento de cursos d'água.

Muitos trabalhos já foram feitos para o monitoramento do uso da terra em diversos locais do Brasil, com diversos objetivos, e os resultados são sempre promissores e atendem muito além dos resultados esperados no início (DIAS \& OLIVEIRA, 2015; FERNANDES et al. 2015; ARRAES et al. 2010, FUJACO et al. 2010, MENKE et al. 2009). 
Alguns municípios da microrregião de Itabira (Itabira, Barão de Cocais, Santa Bárbara, São Gonçalo do Rio Abaixo, João Monlevade, Rio Piracicaba e Bela Vista de Minas) apresentam áreas de mineração, causando tanto impactos positivos na economia como possíveis negativos no meio ambiente e agricultura. Além disso, a alta dependência dos municípios em relação às empresas mineradoras, pode prejudicar o desenvolvimento da diversificação de setores como a agricultura e pecuária. Assim, o conhecimento de como está sendo utilizado outras áreas dos municípios é de extrema importância, tanto para potencializar usos atuais como identificar áreas promissoras, já que a mineração é um recurso findável.

ROSSATO et al. (2009) analisando as diferenças das condições socioeconômicas da população das microrregiões do Estado de Minas Gerais para o ano 2000, demonstrou que as microrregiões de Minas Gerais, em sua maioria, não apresentaram condições favoráveis quanto aos indicadores de condições do domicílio, industrialização e urbanização e de infraestrutura de saúde. A microrregião de Itabira apresentou índice positivo apenas para Industrialização e Urbanização. Considerando que a região apresenta alta dependência da atividade mineral, MELLO (2000) e MARTINS (2003) acreditam que esta não gera um polo de desenvolvimento, e sim um enclave econômico. Um enclave econômico caracteriza-se pela ausência de ligações em cadeia entre a atividade principal (neste caso, a mineração) e os outros setores econômicos da região na qual a empresa está inserida. Uma região que se configura como enclave econômico não desfruta de um desenvolvimento autossustentável, diversificado e independente da atividade principal. Enclave econômico não pressupõe subdesenvolvimento, apenas dependência.

ALVARENGA (2006) analisou a Vulnerabilidade Econômica do Município de Itabira e todos os indicadores que foram desenvolvidos para quantificar a vulnerabilidade econômica de Itabira em relação à atividade mineral foram unânimes em indicar significativa dependência econômica, o que valida as teorias que modelam o desenvolvimento dos municípios mineradores. Além de mostrarem grande vulnerabilidade econômica, nenhum indicador analisado apresentou em sua evolução histórica indícios de diminuição ou aumento da vulnerabilidade econômica nos últimos cinco anos.

Nesse contexto, é de extrema importância a identificação das principais mudanças no uso da terra, em um período de 30 anos, para cada município com áreas de crescimento de mineração. Assim, o trabalho teve por objetivo identificar se houve mudanças no uso da terra em municípios com áreas de mineração na microrregião de Itabira, que possam ter 
gerado desenvolvimento além ou devido à mineração. Dentre essas mudanças: instalação de novas áreas de mineração, crescimento das cidades, desmatamento, diversificação da agropecuária, pastagens, etc.

\section{METODOLOGIA}

O presente trabalho analisou os municípios de Itabira, Barão de Cocais, Santa Bárbara, São Gonçalo do Rio Abaixo, João Monlevade, Rio Piracicaba e Bela Vista de Minas, pertencentes à microrregião de Itabira, apresentados no mapa de localização da Figura 1. Nessa região estão presentes duas grandes empresas de mineração, sendo uma empresa Arcelor Mittal e a outra a Vale. Os outros municípios foram incluídos pois a área de mineração, além de estar presente em divisas entre municípios, a distância entre municípios é pequena, podendo ter moradores que trabalham nas mineradoras.

Figura 1: Área de estudo, representado pelos municípios de Itabira, Barão de Cocais, Santa Bárbara, São Gonçalo do Rio Abaixo, Rio Piracicaba, João Monlevade e Bela Vista de Minas, integrando a microrregião do médio rio Piracicaba no estado de Minas Gerais

$$
43.5-43.0
$$

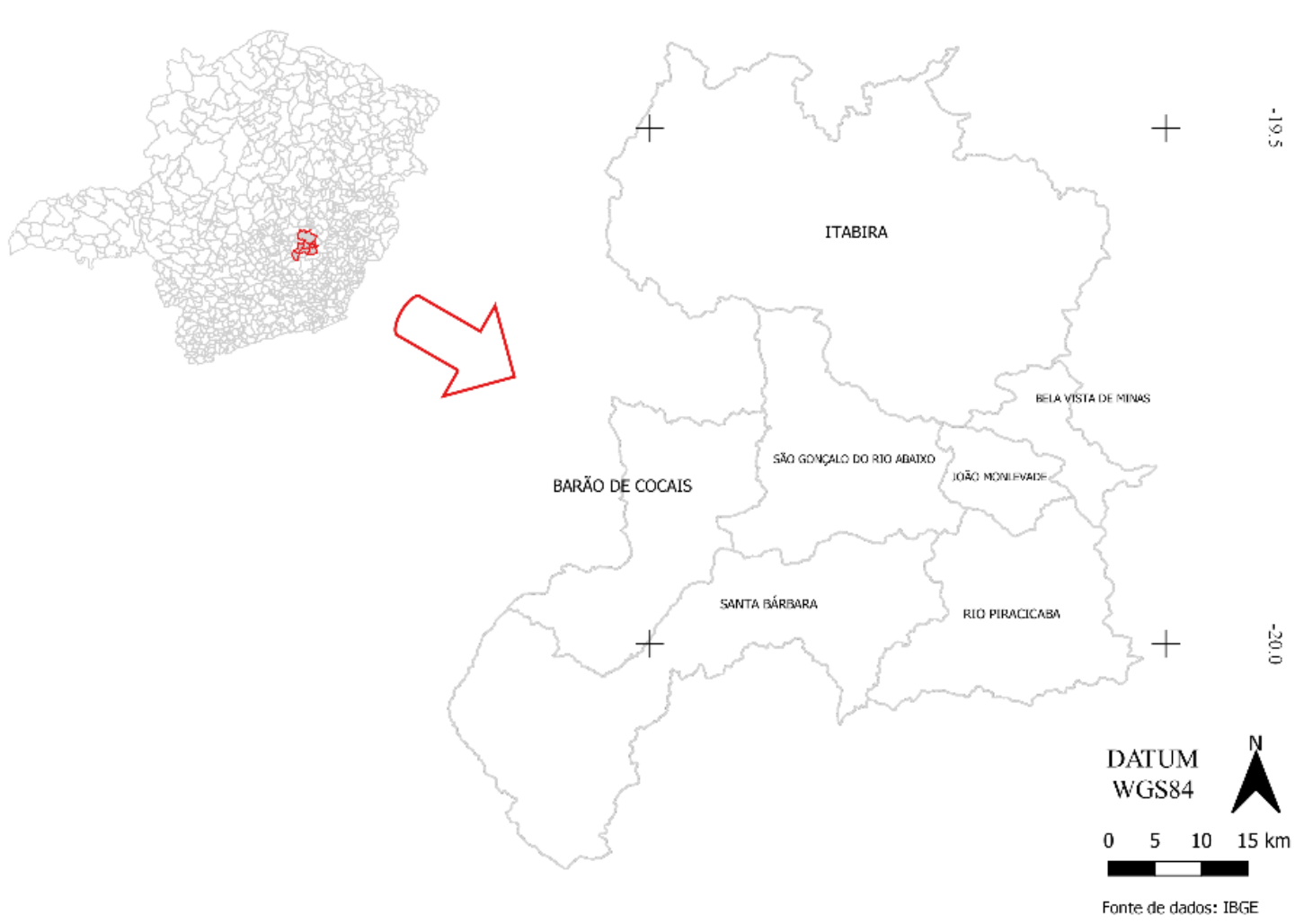

Fonte: Elaboração própria. 
O fluxograma do trabalho (Figura 2) mostra as etapas realizadas para obtenção dos resultados. Foram utilizadas técnicas de geoprocessamento, e uso do software QGIS (QGIS, 2020); além de imagens do MAPBIOMAS para geração de mapas uso da terra, para os anos de 1987, 1997, 2007 e 2017, de modo a permitir uma análise de 30 anos do uso da cobertura da terra.

O geoprocessamento pode ser entendido como a utilização de técnicas matemáticas e computacionais para tratar dados obtidos de objetos ou fenômenos geograficamente identificados ou extrair informações desses objetos ou fenômenos, quando são observados por um sistema sensor (MOREIRA, 2007).

Figura 2: Fluxograma do trabalho

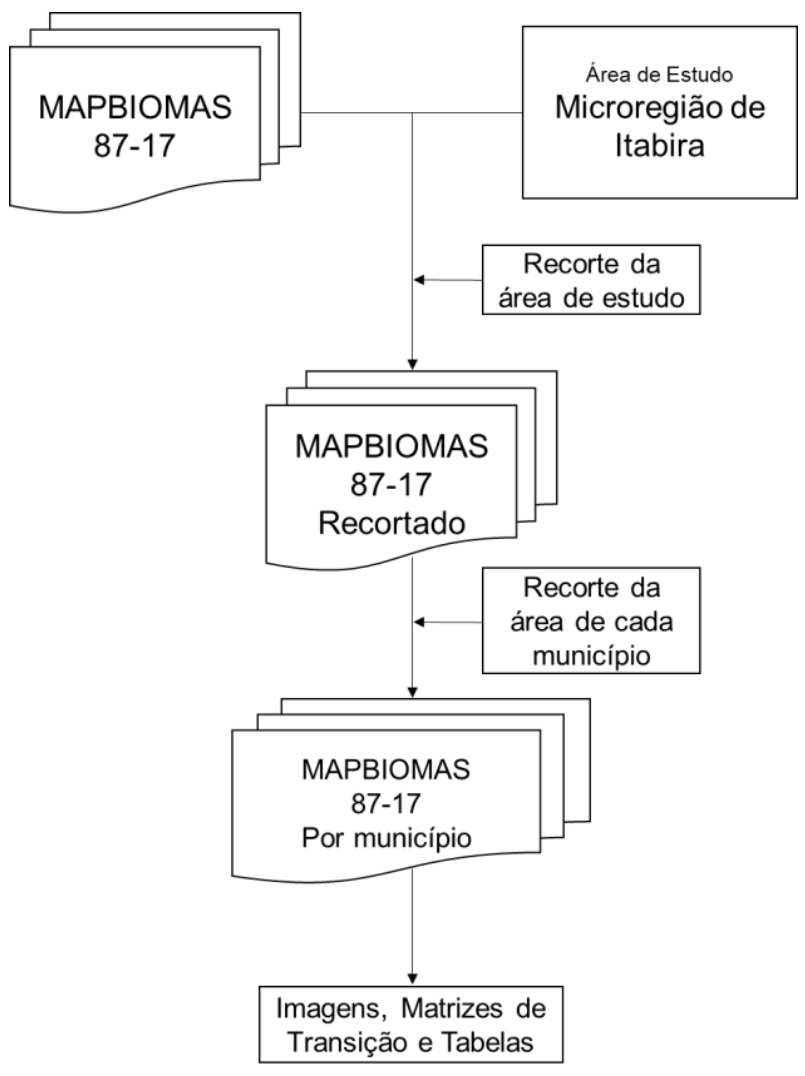

Fonte: Elaboração própria.

O MAPBIOMAS é uma iniciativa que envolve uma rede colaborativa com especialistas nos biomas, usos da terra, sensoriamento remoto, SIG (Sistema de Informação Geográfica) e ciência da computação. Estes, utilizam processamento em nuvem e classificadores automatizados desenvolvidos e operados a partir da plataforma Google Earth Engine para gerar uma série histórica de mapas anuais de cobertura e uso da terra do Brasil. 
Os mapas têm sua melhor aplicação em escalas até 1:100.000 e são gerados a partir de imagens LANDSAT 8, com resolução espacial de 30 metros. Assim, cada pixel das imagens é classificado, entre 27 classes de uso da terra (MAPBIOMAS, 2019).

Pelo fluxograma do trabalho, a partir dos vetores de cada município, foi recortada as imagens do MAPBIOMAS e para cada imagem foi processado de maneira a extrair, com o uso do SIG, a área de cada tipo de uso da terra para os anos de 1987, 1997, 2007 e 2017. Também foi gerada a matriz de transição comparando os anos de 1987 e 2017 para cada município, de modo a permitir a identificação do que havia na bacia em 1987 e foi substituído ou mantido em 2017.

\section{RESULTADOS E DISCUSSÃO}

As Figuras 3 e 4 (a seguir), apresentam o mapa de uso da terra para os municípios da área de estudo, nos anos de 1987 e 2017, respectivamente.

Figura 3: Mapa de uso da terra para os municípios da área de estudo

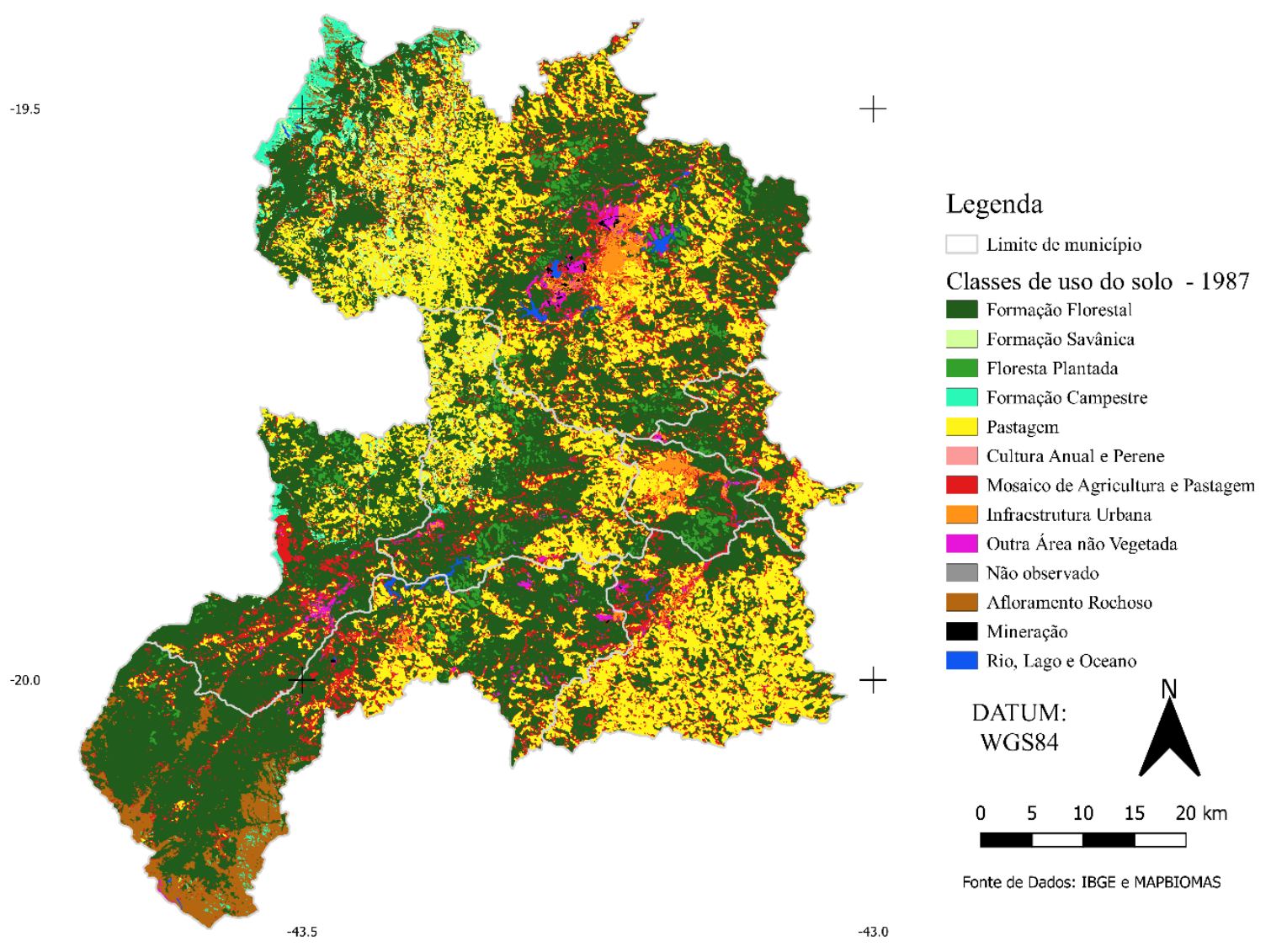

Fonte: Elaboração própria. 
Figura 4: Mapa de uso da terra para os municípios da área de estudo

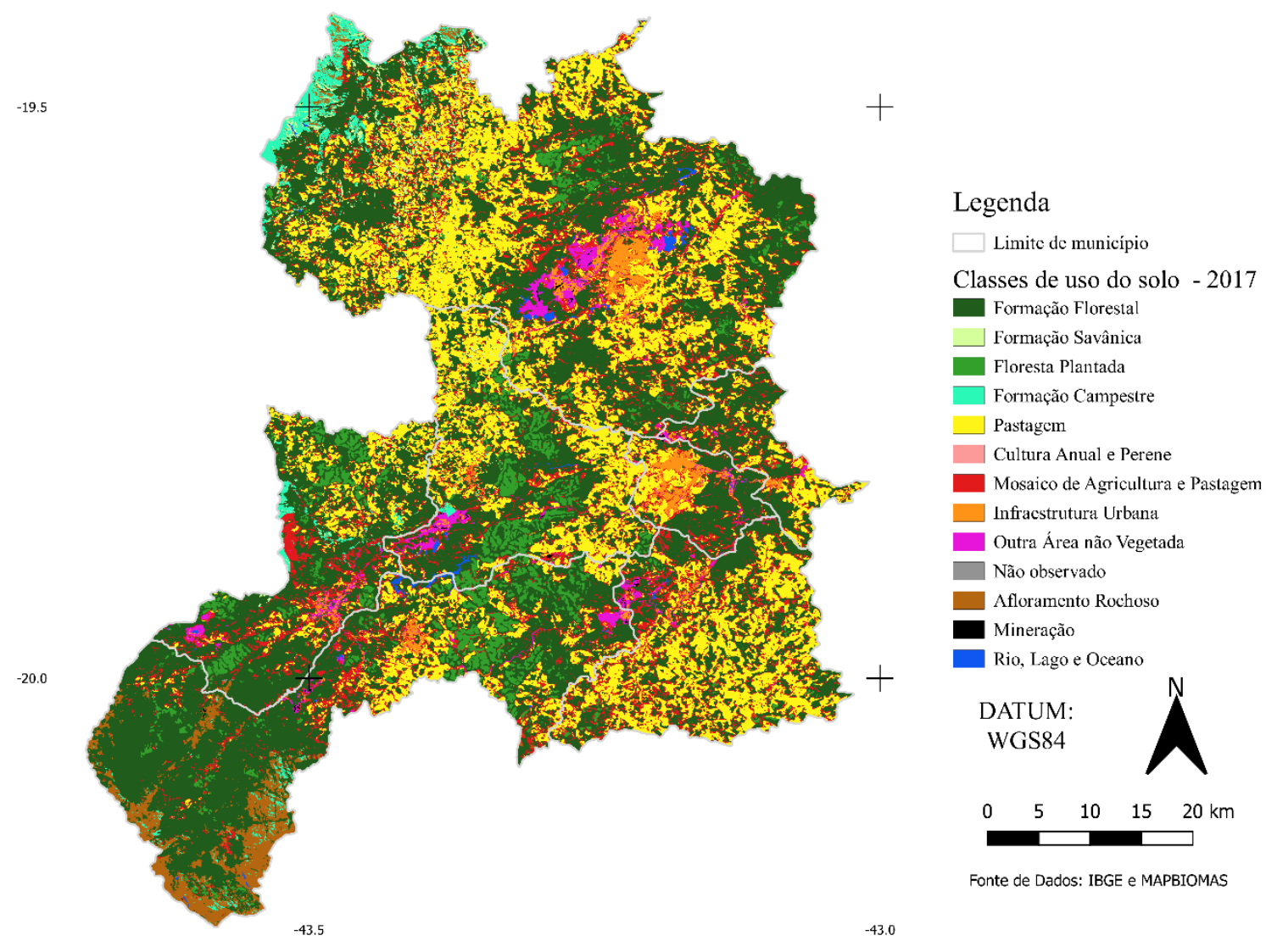

Fonte: Elaboração própria.

Analisando as Figuras 3 e 4, nota-se, visualmente, que há pouca alteração no uso da terra nos 30 anos de intervalo entre as imagens. Porém há destaques a serem notados como: aumento da infraestrutura urbana, com destaque a Itabira, João Monlevade, Barão de Cocais e Santa Bárbara. A maioria dos municípios analisados possuem poucos habitantes, com menos de 30 mil, e economia baseada principalmente na extração de minérios. $O$ SIDRA/IBGE (2019) disponibiliza a população estimada entre 2001 e 2018. No Brasil houve um aumento de $21 \%$ da população no período citado. Conforme gráfico da Figura 5, nota-se que a população dos municípios com presença de mineradoras, aumentou acima da média nacional, e outros, apesar de possuírem mineração, estas são distantes dos centros destes e os funcionários acabam por residirem em outros municípios maiores, prejudicando o desenvolvimento econômico, social e com impactos em seu território.

A Tabela 1 mostra a arrecadação do CFEM (Compensação Financeira pela Exploração de Recursos Minerais) em cada município da área de estudo. Com exceção de João Monlevade, onde a área de mineração é mínima e não possui registros de CFEM, foi analisada a arrecadação pontual para o ano de 2003 e para o ano de 2016 . O ano final foi definido como 2016 pois em 2017 foi promulgada a lei 13.540/17 que diminui a arrecadação 
dos municípios e que foi alterada em posteriormente para compensação de perdas. (MME, 2020; ANM, 2020).

Tabela 1: Dados de arrecadação do CFEM para os anos de 2003 e 2016 nos municípios da área de estudo

\begin{tabular}{|c|c|c|}
\hline \multicolumn{3}{|c|}{ Arrecadação CFEM (Compensaç̃o Financeira pela Exploração de Recursos Minerais)* } \\
\hline Município & Valor Anual (em Reais) 2003 & Valor Anual (em Reais) 2016 \\
\hline Itabira & $10.088 .304,37$ & $141.090 .963,40$ \\
\hline São Gonçalo do Rio Abaixo & $1.026 .758,40$ & $53.124 .773,23$ \\
\hline Santa Bárbara & $3.067 .118,21$ & $11.980 .621,97$ \\
\hline Rio Piracicaba & $412.989,28$ & $9.357 .948,40$ \\
\hline Bela Vista de Minas & $162.003,26$ & $1.861 .853,30$ \\
\hline Barão de Cocais & $2.010 .473,51$ & $12.836 .439,30$ \\
\hline João Monlevade & - & - \\
\hline
\end{tabular}

Fonte: Elaboração própria.

Figura 5: População estimada em 2001 (colunas em azul) e 2018 (colunas em vermelho) e o crescimento, indicado pela porcentagem, para cada município (dados: SIDRA/IBGE).

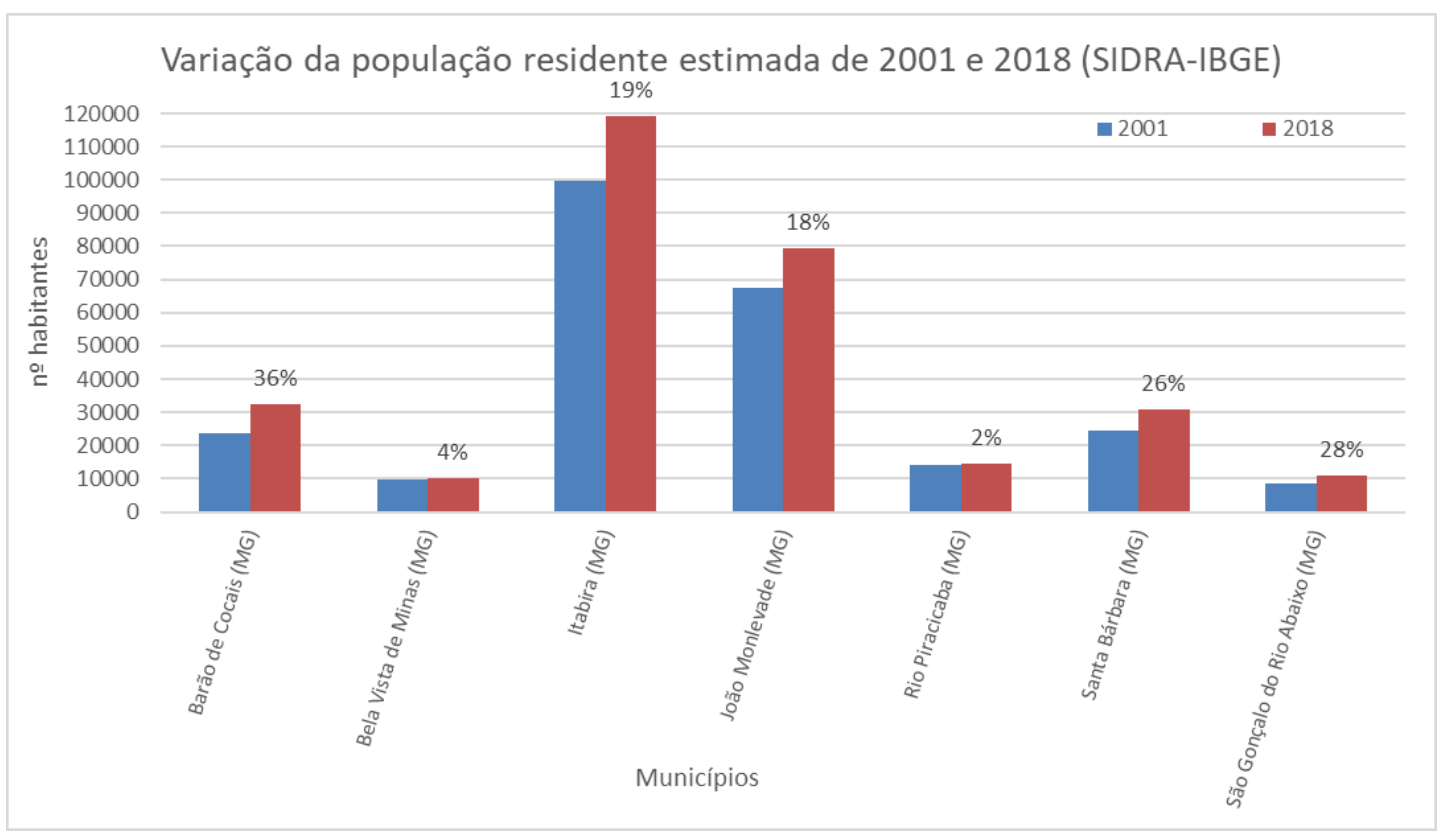

Fonte: Elaboração própria.

Há também um crescimento notável, visualmente, da floresta plantada sobre áreas de formação florestal, indicando um desflorestamento do bioma mata atlântica. Por outro lado, manchas de formação florestal sobre pastagem aumentaram, indicando abandono de pastos (baixa produtividade) e adequações ao código florestal.

Foram geradas as matrizes de transição das classes de uso da terra, considerando toda área de cada município, objeto deste estudo, para o ano de 1987 em relação a 2017 (Tabelas 
de 2 a 8). Esta foi gerada no QGIS, com a ferramenta r.kappa do GRASS. Essa ferramenta compara e contabiliza, em número de pixels, as imagens de 1987 e 2017, para cada tipo de uso da terra, gerando uma matriz de confusão, chamada de transição. A área para cada classe da matriz, é obtida dividindo a área total do município pelo total de pixels encontrados em cada município, a partir de uma planilha de cálculo (Excel). Dessa maneira, a área pode diferir em poucos metros quadrados em relação às áreas contabilizadas nas Figuras 6 a 12, por município. Para isso foi utilizada a ferramenta r.report do GRASS, que após processada, tem como saída uma Tabela com número do pixel e a área de cada conjunto de pixels.

Essa análise permite verificar as alterações na cobertura do uso da terra localmente, ou seja, que tipo de classe havia em 1987 em determinado local, e sua classificação em 2017. Nesse sentido, os cruzamentos entres mesmas classes, representam as áreas onde não se alterou o tipo de cobertura nos últimos 30 anos (diagonal da Tabela), por exemplo: a área de mineração em Barão de Cocais (Tabela 2), apresenta aproximadamente 5,6 hectares no ano de 2017 e zero em 1987, indicando áreas novas de mineração, iniciadas nos últimos 30 anos no município. Segundo DINIZ et al. (2014), analisando o crescimento das áreas mineradas no quadrilátero ferrífero em Minas Gerais, por meio do uso de sensoriamento remoto, não havia áreas de mineração ativa em 1989. A mina de Gongo Soco, localizada no município, antes explorada pelo ouro, foram descobertas em 1967 reservas de minério de ferro, mas somente em 1989 foi iniciada a exploração e novas áreas abertas anos depois (ARAUJO \& MORAIS, 2016).

A Tabela 2, analisada na horizontal, indica o total ocupado por cada classe em 1987 (coluna Soma 1987); e os valores ao longo da linha, representam a área por qual classe de uso da terra foi substituída em 2017. Assim, se a área diminuiu de 1987 para 2017, pode-se analisar por qual foi substituída. Na vertical, indica o total ocupado por classe em 2017 (linha Soma 2017); e os valores ao longo da coluna, representam a área por qual classe de uso de solo a classe da respectiva coluna aumentou, ou seja, áreas novas sobrepondo outras. Portanto, na coluna, as áreas sobre o qual a respectiva classe aumentou; e na linha, as áreas sobre o qual a respectiva classe perdeu área.

As Figuras 6, 7, 8, 9, 10, 11 e 12, mostram a variação da área de cada tipo de uso de solo identificado por município, para os anos de 1987, 1997, 2007 e 2017. Isso permite analisar como cada uso variou ao longo dos últimos 30 anos. Vale salientar que algumas Tabelas foram na medida de hectares e outras em quilômetros quadrados, já que a área dos municípios difere. 
Tabela 2: Matriz de transição indicando a variação da cobertura da terra (em hectares) para os anos de 1987 e 2017 no município de Barão de Cocais

\begin{tabular}{|c|c|c|c|c|c|c|c|c|c|c|c|c|c|c|c|}
\hline & & \multicolumn{13}{|c|}{2017} & \multirow[b]{2}{*}{ Soma 1987} \\
\hline & Classe & 3 & 4 & 9 & 12 & 15 & 19 & 21 & 24 & 25 & 27 & 29 & 30 & 33 & \\
\hline \multirow{14}{*}{$\begin{array}{l}\stackrel{\infty}{\infty} \\
\stackrel{-}{2}\end{array}$} & 3 & $17.404,69$ & 59,86 & $1.992,96$ & 84,53 & $1.336,75$ & 0,84 & $1.777,00$ & 52,12 & 269,34 & 5,98 & 15,58 & 0,59 & 18,86 & $23.019,09$ \\
\hline & 4 & 116,10 & 123,43 & 4,13 & 12,54 & 88,82 & - & 48,41 & 0,08 & - & - & - & - & - & 393,52 \\
\hline & 9 & 33,59 & - & 590,79 & - & 3,37 & - & 5,22 & - & 9,60 & - & - & - & - & 642,57 \\
\hline & 12 & 28,29 & 22,48 & 3,03 & 452,29 & 12,46 & - & 31,07 & 0,08 & - & - & - & - & - & 549,70 \\
\hline & 15 & 890,10 & 20,96 & 209,73 & 29,55 & $2.588,04$ & 1,94 & 809,02 & 23,15 & 12,63 & 0,42 & 1,43 & 0,76 & 1,35 & $4.589,08$ \\
\hline & 19 & - & - & - & - & - & - & - & - & - & - & - & - & - & - \\
\hline & 21 & 976,15 & 7,49 & 94,80 & 86,55 & 443,87 & - & $2.470,42$ & 84,03 & 81,50 & 1,85 & 10,86 & 2,27 & 0,59 & $4.260,39$ \\
\hline & 24 & 0,76 & 0,59 & - & - & 2,86 & - & 6,31 & 31,07 & 8,34 & - & - & - & - & 49,93 \\
\hline & 25 & 23,74 & - & - & 1,26 & 6,90 & - & 94,47 & 132,52 & 146,08 & - & 3,12 & 0,76 & 0,76 & 409,60 \\
\hline & 27 & 0,93 & - & - & - & 0,67 & - & 0,67 & 0,08 & - & 2,95 & - & - & - & 5,30 \\
\hline & 29 & 8,34 & - & 1,26 & 0,17 & 0,59 & - & 6,90 & - & 0,08 & - & 107,52 & 1,18 & - & 126,04 \\
\hline & 30 & - & - & - & - & - & - & - & - & - & - & - & - & - & - \\
\hline & 33 & 1,68 & 2,02 & - & - & 4,63 & - & 0,25 & - & - & - & - & - & 3,28 & 11,87 \\
\hline & Soma 2017 & $19.484,37$ & 236,84 & $2.896,70$ & 666,90 & $4.488,98$ & 2,78 & $5.249,75$ & 323,14 & 527,56 & 11,20 & 138,50 & 5,56 & 24,84 & $34.057,10$ \\
\hline
\end{tabular}

Legenda: 03-Formação Florestal; 04-Formação Savânica; 09-Floresta Plantada; 12-Formação Campestre; 15-Pastagem; 19-Cultura Anuale Perene; 21-Mosaico de Agricultura e

Pastagem; 24-Infraestrutura Urbana; 25-Outra Área não Vegetada; 27-Não observado; 29-Afloramento Rochoso; 30-Mineração; 33-Rio, Lago e Oceano.

Fonte: Elaboração própria.

Figura 6: Variação da área de cada classe de uso da terra, na área de estudo, nos anos de 1987, 1997, 2007 e 2017 no município de Barão de Cocais

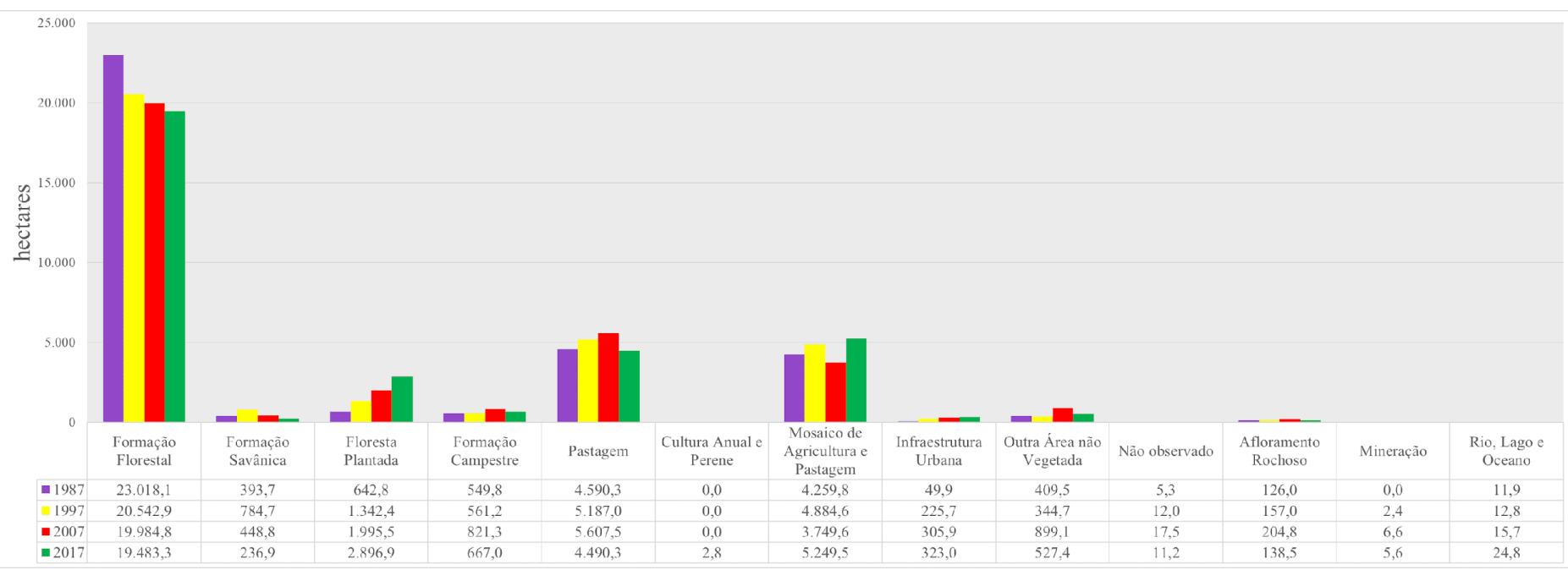

Fonte: Elaboração própria.

No município de Barão de Cocais, analisando a Figura 6, nota-se uma queda entre 1987 e 1997 da área de formação florestal, que segue a tendência até 2017. Na Tabela 2 é possível identificar que a formação florestal foi substituída principalmente pela classe 9 (floresta plantada) em 1993 ha, seguida pela classe 21 (Mosaico de agricultura e pastagem) em 1777 hectares (ha) e pela classe 15 (pastagens) em 1336,7 ha. 
Tabela 3: Matriz de transição indicando a variação da cobertura da terra (em hectares) para os anos de 1987 e 2017 no município de João Monlevade

\begin{tabular}{|c|c|c|c|c|c|c|c|c|c|c|}
\hline & & \multicolumn{8}{|c|}{2017} & \\
\hline & Classe & 3 & 9 & 15 & 21 & 24 & 25 & 30 & 33 & Soma 1987 \\
\hline \multirow{9}{*}{$\begin{array}{l}\hat{\infty} \\
2 \\
-1\end{array}$} & 3 & $3.957,51$ & 7,24 & 375,38 & 488,15 & 33,44 & 41,44 & 1,01 & - & $4.904,17$ \\
\hline & 9 & 477,20 & 2,11 & 31,67 & 197,00 & 0,08 & 1,09 & - & - & 709,15 \\
\hline & 15 & 32,76 & 5,14 & $1.242,61$ & 251,49 & 218,81 & 12,55 & - & - & $1.763,36$ \\
\hline & 21 & 254,35 & 1,85 & 334,02 & 573,47 & 171,81 & 75,88 & 0,34 & - & $1.411,73$ \\
\hline & 24 & 11,71 & - & 26,78 & 57,61 & 831,19 & 61,48 & - & 3,71 & 992,47 \\
\hline & 25 & 15,83 & - & 4,88 & 21,48 & 16,84 & 45,31 & 1,01 & 3,71 & 109,07 \\
\hline & 30 & - & - & - & - & - & 0,67 & - & - & 0,67 \\
\hline & 33 & 18,02 & - & - & 2,19 & 0,08 & 1,09 & - & 2,61 & 24,00 \\
\hline & Soma 2017 & $4.767,39$ & 16,34 & $2.015,35$ & $1.591,38$ & $1.272,26$ & 239,53 & 2,36 & 10,02 & $9.914,63$ \\
\hline
\end{tabular}

Legenda: 03-Formação Florestal; 09-Floresta Plantada; 15-Pastagem; 21-Mosaico de Agricultura e Pastagem; 24Infraestrutura Urbana; 25-Outra Área não Vegetada; 30-Mineração; 33-Rio, Lago e Oceano.

Fonte: Elaboração própria.

Figura 7: Variação da área de cada classe de uso da terra, na área de estudo, nos anos de 1987, 1997, 2007 e 2017 no município de João Monlevade

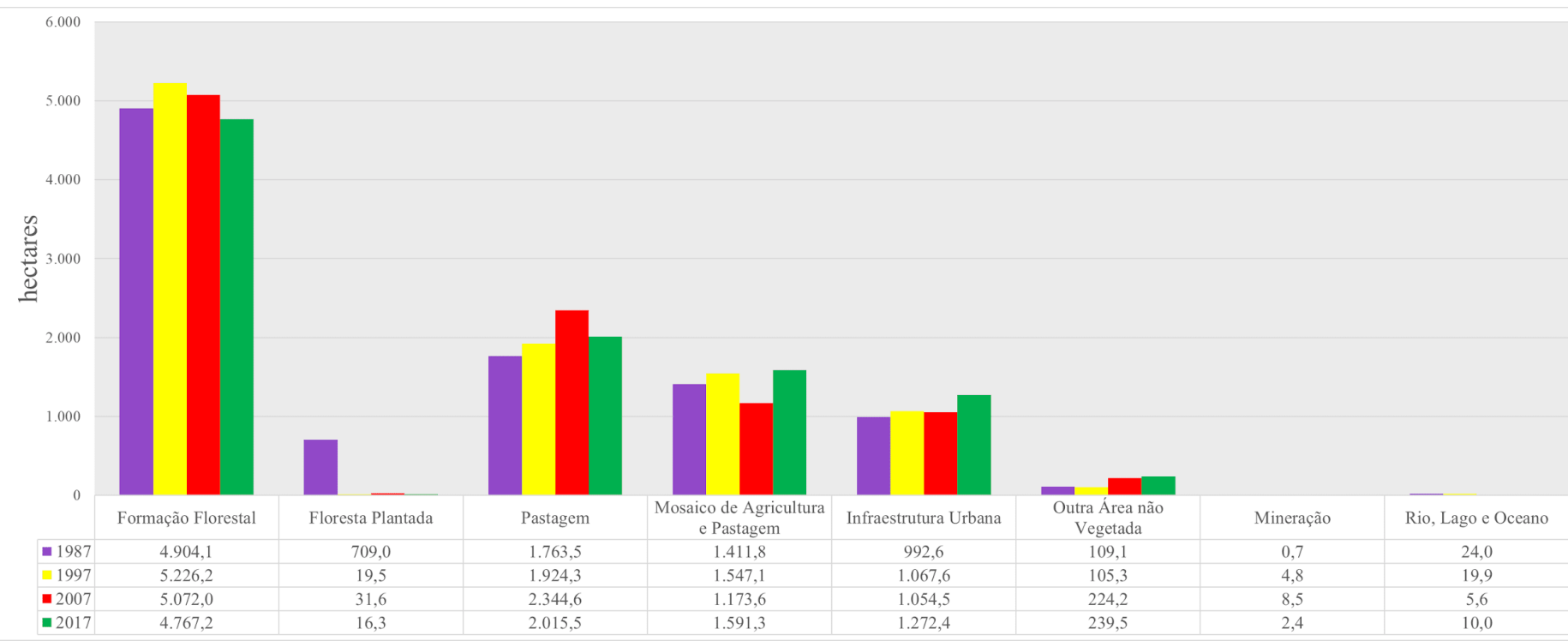

Fonte: Elaboração própria.

A Tabela 3 e a Figura 7 mostram a análise da mudança de uso da terra para João Monlevade, que possui uma área relativamente pequena e praticamente ocupada por zona urbana. Sendo a área do município de aproximadamente 9914 hectares, no ano 1987 a zona urbana ocupava praticamente 10\% do território, sendo que em 2017 aumentou para 12,8\% com 1272,4 hectares.

Em 1987 havia 709 hectares de floresta plantada, que acabou substituída, observando a Tabela 3, por formação florestal e mosaico de agricultura e pastagem. Isso pode indicar um leve aumento da atividade agropecuária, apesar do pequeno território do município. 
Tabela 4: Matriz de transição indicando a variação da cobertura da terra (em hectares) para os anos de 1987 e 2017 no município de Itabira

\begin{tabular}{|c|c|c|c|c|c|c|c|c|c|c|c|c|c|c|}
\hline & & \multicolumn{12}{|c|}{2017} & \\
\hline & Classe & 3 & 4 & 9 & 12 & 15 & 21 & 24 & 25 & 27 & 29 & 30 & 33 & Soma 1987 \\
\hline \multirow{13}{*}{$\stackrel{\infty}{\infty}$} & 3 & $44.124,34$ & 387,90 & $1.381,81$ & 159,07 & $5.410,26$ & $4.826,85$ & 120,95 & 572,36 & 2,28 & 0,67 & 31,04 & 121,37 & $57.138,90$ \\
\hline & 4 & $1.177,53$ & $1.813,99$ & 27,41 & 160,00 & 779,34 & 533,39 & 0,17 & - & 0,25 & 0,17 & - & 2,95 & $4.495,21$ \\
\hline & 9 & $1.119,16$ & - & $\mathbf{9 9 9 , 7 3}$ & - & 109,06 & 217,27 & 1,52 & 22,77 & - & - & 1,86 & 8,27 & $2.479,64$ \\
\hline & 12 & 141,70 & 141,02 & 4,64 & $3.310,00$ & 94,55 & 125,42 & 0,84 & - & 0,17 & 1,43 & - & 0,17 & $3.819,95$ \\
\hline & 15 & $3.421,84$ & 87,38 & 370,27 & 171,81 & $25.548,71$ & $5.369,44$ & 336,96 & 72,54 & 0,34 & 4,13 & 3,80 & 22,52 & $35.409,73$ \\
\hline & 21 & $5.128,89$ & 45,97 & 179,82 & 218,70 & $4.134,30$ & $6.194,32$ & 305,16 & 365,04 & 0,25 & 0,84 & 13,07 & 84,34 & $16.670,72$ \\
\hline & 24 & 74,14 & - & - & - & 140,43 & 276,06 & $1.427,02$ & 275,55 & - & - & 16,53 & 3,04 & $2.212,77$ \\
\hline & 25 & 239,79 & - & 1,27 & - & 88,39 & 307,27 & 83,42 & 483,88 & - & - & 19,99 & 20,83 & $1.244,84$ \\
\hline & 27 & 0,42 & - & - & 0,25 & 0,42 & 0,59 & - & - & 3,04 & - & - & - & 4,72 \\
\hline & 29 & 0,76 & 0,25 & 3,54 & 5,90 & 2,19 & 1,94 & 0,67 & - & - & 942,55 & - & - & 957,81 \\
\hline & 30 & 19,65 & - & - & - & 9,19 & 49,85 & 62,08 & 120,27 & - & - & 8,94 & - & 269,99 \\
\hline & 33 & 13,66 & 13,07 & - & 0,76 & 6,92 & 77,26 & 5,90 & 221,23 & - & - & 2,78 & 325,57 & 667,16 \\
\hline & Soma 2017 & $55.461,89$ & $2.489,59$ & $2.968,49$ & $4.026,51$ & $36.323,76$ & $17.979,66$ & $2.344,68$ & $2.133,66$ & 6,33 & 949,80 & 98,01 & 589,06 & $125.371,44$ \\
\hline
\end{tabular}

Legenda: 03-Formação Florestal; 04-Formação Savânica; 09-Floresta Plantada; 12-Formação Campestre; 15-Pastagem; 19-Cultura Anual e Perene; 21-Mosaico de Agric ultura e Pastagem; 24-Infraestrutura Urbana; 25-Outra Área não Vegetada; 27-Não observado; 29-Afloramento Rochoso; 30-Mineração; 33-Rio, Lago e Oc eano.

Fonte: Elaboração própria.

Figura 8: Variação da área de cada classe de uso da terra, na área de estudo, nos anos de 1987, 1997, 2007 e 2017 no município de Itabira



Fonte: Elaboração própria.

Para o município de Itabira, avaliando a Tabela 4 e Figura 8, há pouca mudança significativa dentre todos os tipos de uso da terra entre 1987 e 2017. Apenas um aumento na área de floresta plantada, em $5 \mathrm{~km}^{2}$ nos últimos 30 anos. Apesar do relevo acidentado do município, há pouco desenvolvimento de atividade agropecuárias (em expansão de área), o que pode criar uma dependência externa de produtos agrícolas e pouco desenvolvimento de outras atividades. A infraestrutura urbana entre 1987 e 2017 aumentou que a zona urbana 
em $1,32 \mathrm{~km}^{2}$ indicando crescimento, porém, conforme afirmado anteriormente, estar em um enclave econômico.

Tabela 5: Matriz de transição indicando a variação da cobertura da terra (em hectares) para os anos de 1987 e 2017 no município de Bela Vista de Minas

\begin{tabular}{|c|c|c|c|c|c|c|c|c|c|c|}
\hline & & \multicolumn{8}{|c|}{2017} & \\
\hline & Classe & 3 & 9 & 15 & 21 & 24 & 25 & 30 & 33 & Soma 1987 \\
\hline \multirow{9}{*}{$\begin{array}{l}\infty \\
\infty \\
-\end{array}$} & 3 & $4.603,19$ & 5,22 & 425,85 & 600,48 & 22,49 & 36,06 & 4,72 & 0,67 & $5.698,69$ \\
\hline & 9 & 182,81 & 1,18 & 40,69 & 65,54 & 0,08 & 2,27 & - & - & 292,58 \\
\hline & 15 & 414,47 & 28,22 & $1.824,45$ & 481,19 & 7,08 & 8,34 & 0,59 & - & $2.764,34$ \\
\hline & 21 & 819,34 & 4,21 & 384,40 & 679,75 & 19,80 & 52,23 & 5,73 & 0,08 & $1.965,55$ \\
\hline & 24 & 0,08 & - & 3,29 & 9,69 & 86,85 & 3,03 & 2,19 & - & 105,13 \\
\hline & 25 & 9,94 & - & 6,23 & 19,71 & 1,35 & 29,15 & 11,54 & - & 77,92 \\
\hline & 30 & - & - & - & - & 2,19 & 2,19 & $\mathbf{0 , 1 7}$ & - & 4,55 \\
\hline & 33 & 3,03 & - & - & 0,42 & - & 2,11 & - & 0,76 & 6,32 \\
\hline & Soma 2017 & $6.032,88$ & 38,84 & $2.684,90$ & $1.856,79$ & 139,84 & 135,38 & 24,94 & 1,52 & $10.915,08$ \\
\hline
\end{tabular}

Legenda: 03-Formação Florestal; 09-Floresta Plantada; 15-Pastagem; 21-Mosaico de Agricultura e Pastagem; 24Infraestrutura Urbana; 25-Outra Área não Vegetada; 30-Mineração; 33-Rio, Lago e Oceano.

Fonte: Elaboração própria.

Figura 9: Variação da área de cada classe de uso da terra, na área de estudo, nos anos de 1987, 1997, 2007 e 2017 no município de Bela Vista de Minas

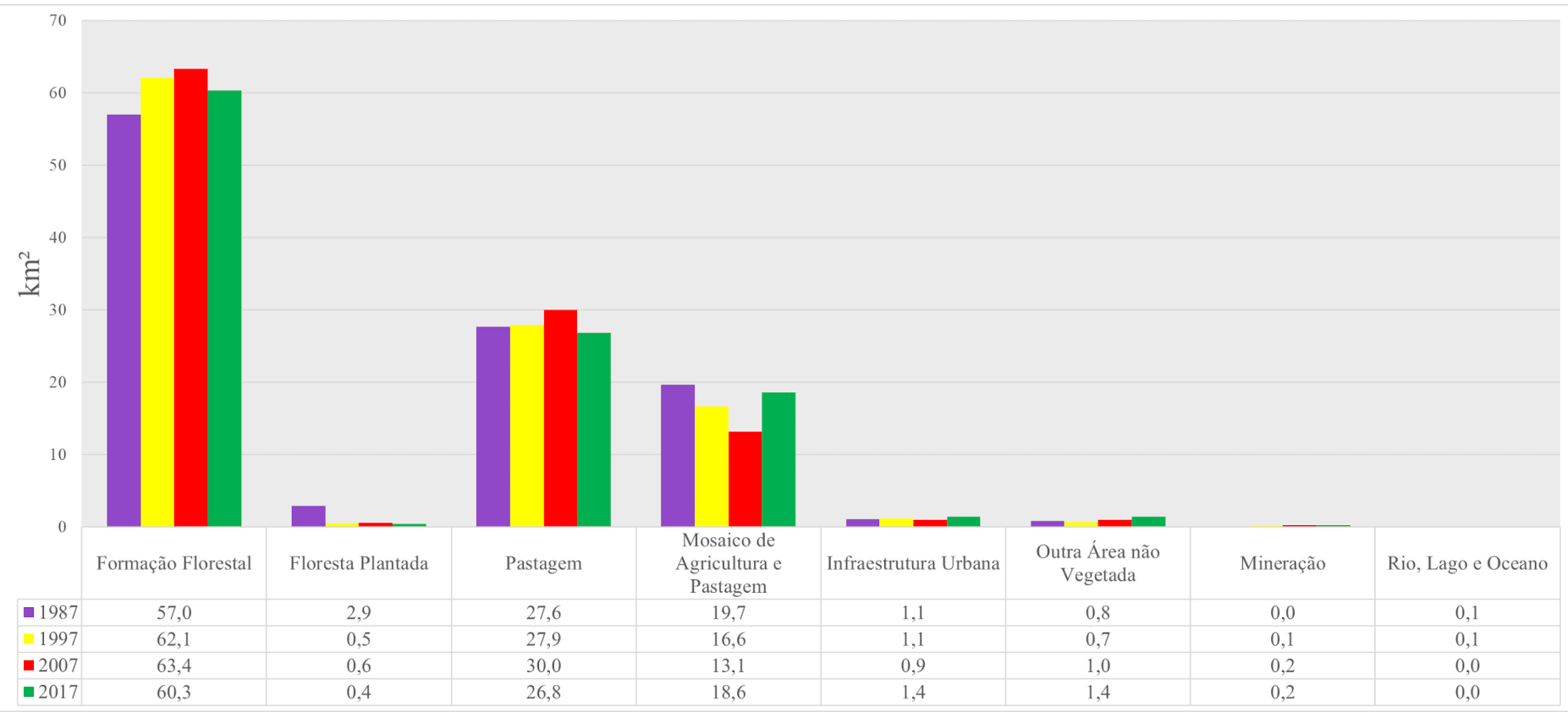

Fonte: Elaboração própria.

O município de Bela Vista de Minas não possui indústria de mineração, porém compartilha com João Monlevade a área da mina explorada pela empresa Arcelor Mittal. Apesar da pouca área de mineração, segundo MARIANO (2014), entre os anos de 2005 e 2011, o Produto Interno Bruto (PIB) do município cresceu 242,7\%, permitindo melhoras na 
infraestrutura urbana e investimentos para a população. Segundo estimativas, o funcionamento da mina pode persistir por 25 anos, permitindo royalties ao município. Esse fato pode permitir nos próximos anos a diversificação e desenvolvimento do município.

Tabela 6: Matriz de transição indicando a variação da cobertura da terra (em hectares) para os anos de 1987 e 2017 no município de Santa Bárbara

\begin{tabular}{|c|c|c|c|c|c|c|c|c|c|c|c|c|c|c|}
\hline & & \multicolumn{12}{|c|}{2017} & \\
\hline & 9 & $1.045,56$ & $1.676,23$ & - & 9,76 & - & 6191 & 4,63 & 2,86 & - & - & 0,59 & - & $2.801,54$ \\
\hline & 15 & 418,43 & 299,81 & 11,10 & $4.500,99$ & 0,17 & $1.030,00$ & 126,18 & 25,24 & 0,93 & 47,95 & 0,08 & 1,51 & $6.462,39$ \\
\hline & 19 & - & - & - & - & - & - & - & - & - & - & - & - & - \\
\hline$\infty$ & 21 & $2.974,58$ & 469,24 & 121,14 & $1.294,65$ & 0,25 & $3.263,88$ & 115,58 & 129,97 & 2,27 & 796,22 & 3,70 & 8,16 & $9.179,64$ \\
\hline & 27 & 1,51 & 0,08 & - & 1,01 & - & 0,84 & - & - & 0,25 & - & - & - & 3,70 \\
\hline & 29 & 515,76 & 140,23 & 321,10 & 1,85 & - & 100,11 & - & 4,54 & - & $6.045,98$ & 3,70 & 21,20 & $7.154,47$ \\
\hline & 30 & - & - & - & - & - & 0,25 & 2,19 & 0,59 & - & - & - & - & 3,03 \\
\hline & 33 & 26,84 & - & - & 0,08 & - & 6,23 & - & 7,49 & - & 4,37 & 0,50 & 225,79 & 271,30 \\
\hline & Soma 2017 & $39.897,13$ & $5.155,21$ & 713,78 & $6.887,88$ & 0,42 & $6.593,71$ & 516,77 & 566,31 & 7,07 & $7.733,15$ & 52,41 & 284,92 & $68.408,76$ \\
\hline
\end{tabular}

Legenda: 03-Formação Florestal; 09-Floresta Plantada; 12-Formação Campestre; 15-Pastagem; 19-Cultura Anual e Perene; 21-Mosaico de Agricultura e Pastagem; 24-Infraestrutura Urbana; 25-Outra Área não Vegetada; 27-Não observado; 29-Afloramento Rochoso; 30-Mineração; 33-Rio, Lago e Oceano.

Fonte: Elaboração própria.

Figura 10: Variação da área de cada classe de uso da terra, na área de estudo, nos anos de 1987, 1997, 2007 e 2017 no município de Santa Bárbara

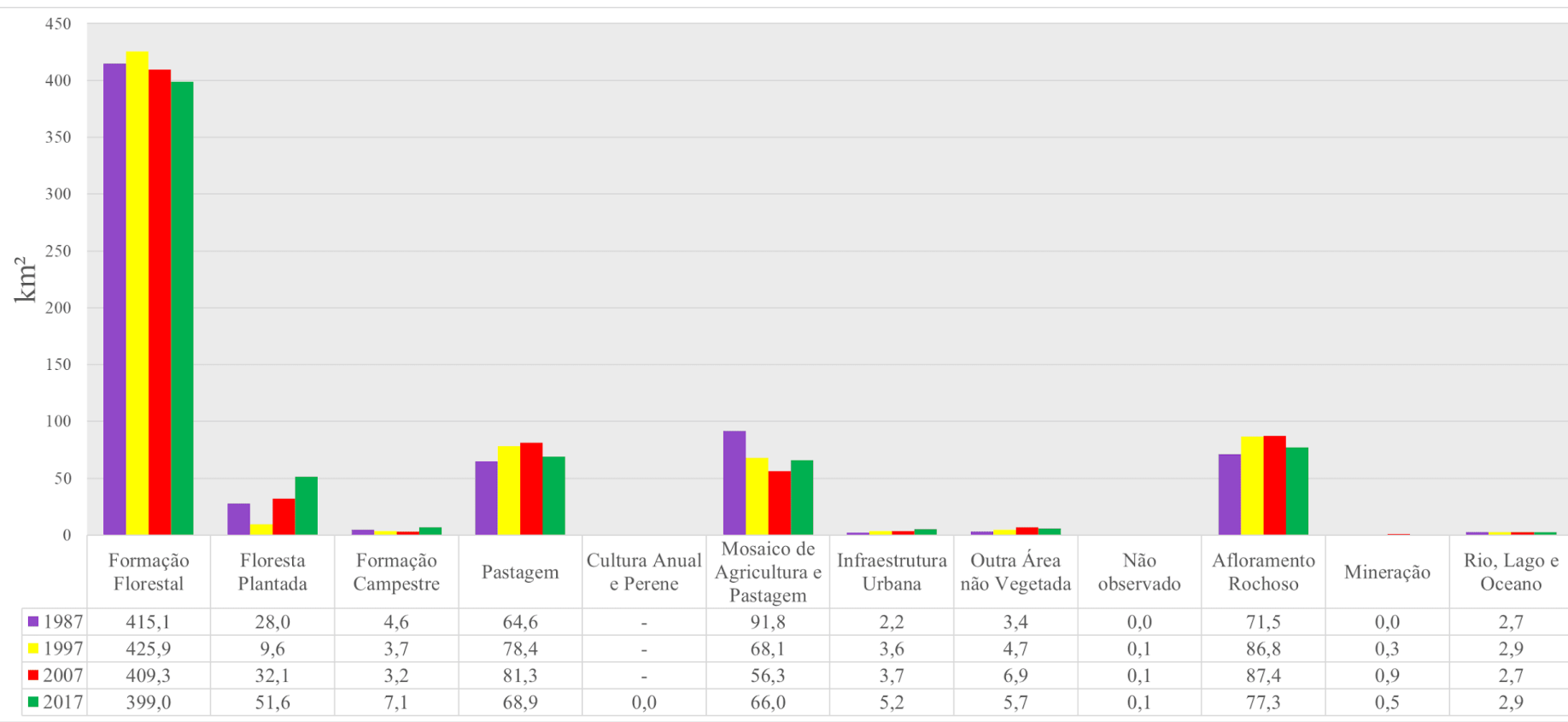

Fonte: Elaboração própria.

Santa Bárbara possui atualmente duas áreas de mineração, sendo uma na parte central de seu território e outra na faixa leste. Verifica-se (analisando a Tabela 6 e Figura 10) que 
boa parte da área de mineração e floresta plantada cresceu sobre formação florestal, ou seja, áreas com mata. Outro fato importante é o crescimento da infraestrutura urbana, saltando de 2,2 $\mathrm{km}^{2}$ em 1987 para 5,7 km², mais que dobrando. Lembrando que o crescimento da população entre 2001 e 2018 foi de $26 \%$.

Tabela 7: Matriz de transição indicando a variação da cobertura da terra (em hectares) para os anos de 1987 e 2017 no município de São Gonçalo do Rio Abaixo

\begin{tabular}{|c|c|c|c|c|c|c|c|c|c|c|c|c|c|}
\hline & & \multicolumn{11}{|c|}{2017} & \\
\hline & Classe & 3 & 4 & 9 & 12 & 15 & 21 & 24 & 25 & 29 & 30 & 33 & Soma 1987 \\
\hline \multirow{9}{*}{$\begin{array}{l}\infty \\
\stackrel{\infty}{\beth}\end{array}$} & 4 & 54,08 & 116,75 & 1,10 & 2,27 & 99,06 & 18,95 & 3,03 & - & 0,08 & - & - & 295,32 \\
\hline & 12 & 3,29 & 1,77 & 0,59 & 42,62 & 6,32 & 3,37 & 2,95 & - & - & 0,17 & - & 61,07 \\
\hline & 15 & 911,32 & 60,31 & 122,56 & 12,63 & $8.268,80$ & $1.258,86$ & 52,14 & 22,66 & 1,43 & 1,35 & 3,37 & $10.715,43$ \\
\hline & 21 & $1.036,99$ & 3,79 & 88,19 & 9,10 & 794,23 & $1.472,64$ & 33,10 & 125,25 & 0,42 & 6,40 & 20,97 & $3.591,10$ \\
\hline & 25 & 11,37 & - & 29,40 & - & 3,71 & 25,44 & 6,74 & 32,77 & - & 14,99 & 2,86 & 127,28 \\
\hline & 29 & 0,67 & - & 17,44 & 0,17 & 2,61 & 1,10 & 11,12 & - & 116,33 & - & - & 149,43 \\
\hline & 30 & - & - & - & - & - & - & - & - & - & - & - & - \\
\hline & 33 & 5,73 & - & - & - & - & 0,59 & - & 0,76 & - & - & 129,30 & 136,37 \\
\hline & Soma 2017 & $15.239,24$ & 279,99 & $3.646,69$ & 132,92 & $11.231,10$ & $4.579,91$ & 196,52 & 663,00 & 120,79 & 51,80 & 239,56 & $36.381,52$ \\
\hline
\end{tabular}

Legenda: 03-Formação Florestal; 04-Formação Savânica; 09-Floresta Plantada; 12-Formação Campestre; 15-Pastagem; 21-Mosaico de Agricultura e Pastagem; 24-Infraestrutura Urbana; 25-Outra Área não Vegetada; 29-Afloramento Rochoso; 30-Mineração; 33-Rio, Lago e Oceano.

Fonte: Elaboração própria.

Figura 11: Variação da área de cada classe de uso da terra, na área de estudo, nos anos de 1987, 1997, 2007 e 2017 no município de São Gonçalo do Rio Abaixo

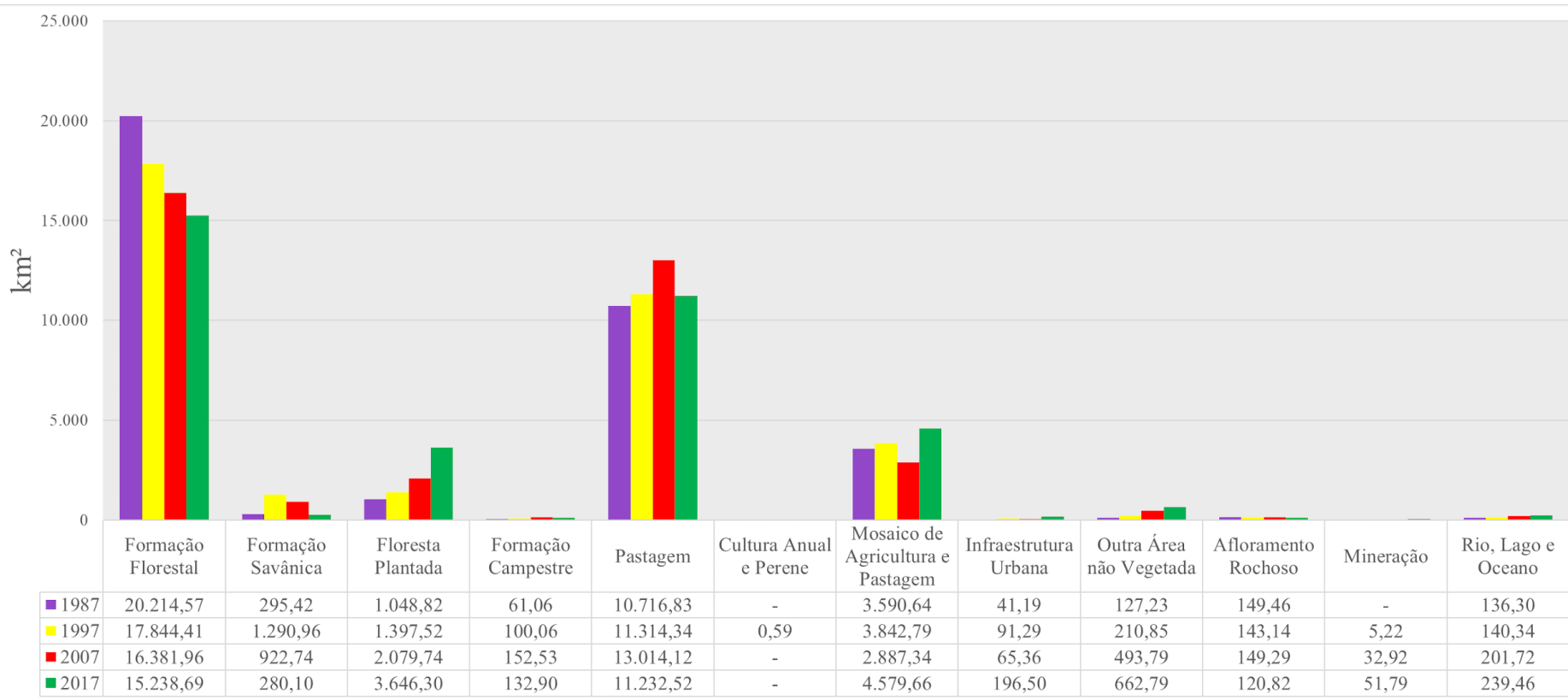

Fonte: Elaboração própria.

Acompanhando o município de Santa Bárbara, São Gonçalo do Rio Abaixo tem um expressivo aumento na área de mineração no período. O município possui uma das maiores 
minas a céu aberto do Brasil, inaugurada no ano de 2006. Após esse ano, pode-se verificar um grande aumento na área de infraestrutura urbana, floresta plantada e mosaico de agricultura e pastagem; e queda na formação florestal e pastagem (Tabela 7 e Figura 11).

Segundo SIQUEIRA (2019), em 2019 com a paralisação da mineração devido ao potencial de rompimento de barragem no município, houve impactos na arrecadação, onde depende $95 \%$ das receitas da mineração. Atualmente o município fomenta projetos do setor industrial e do agronegócio de modo a diversificar e desenvolver o município, gerando menor dependência.

Tabela 8: Matriz de transição indicando a variação da cobertura da terra (em hectares) para os anos de 1987 e 2017 no município de Rio Piracicaba

\begin{tabular}{|c|c|c|c|c|c|c|c|c|c|c|c|c|c|}
\hline & & \multicolumn{11}{|c|}{2017} & \\
\hline & Classe & 3 & 9 & 12 & 15 & 21 & 24 & 25 & 27 & 29 & 30 & 33 & Soma 1987 \\
\hline \multirow{9}{*}{$\begin{array}{l}\stackrel{\infty}{\infty} \\
\curvearrowright\end{array}$} & 9 & 139,02 & 11,78 & - & 12,12 & 56,72 & 0,08 & 22,05 & - & - & 2,69 & - & 244,46 \\
\hline & 15 & $2.350,56$ & 304,55 & - & $11.333,15$ & $3.057,37$ & 25,83 & 5,72 & 0,67 & 9,17 & - & 0,76 & $17.087,79$ \\
\hline & 21 & $2.058,64$ & 47,29 & 1,01 & $2.026,83$ & $2.669,00$ & 50,49 & 118,24 & 0,67 & 1,60 & 12,62 & 10,60 & $6.996,99$ \\
\hline & 24 & 15,90 & - & - & 13,80 & 49,73 & 87,52 & 26,51 & - & - & 0,93 & - & 194,39 \\
\hline & 27 & 1,01 & - & - & 0,76 & 0,93 & - & - & 0,17 & - & - & - & 2,86 \\
\hline & 29 & 0,93 & - & - & 5,97 & 2,10 & - & - & - & - & - & - & 9,00 \\
\hline & 30 & 0,42 & - & - & - & - & - & 0,93 & - & - & - & - & 1,35 \\
\hline & 33 & 14,31 & - & - & - & 0,50 & 0,34 & 2,10 & - & - & - & - & 17,25 \\
\hline & Soma 2017 & $13.915,55$ & 503,57 & 1,51 & $14.729,90$ & $7.492,82$ & 186,31 & 389,12 & 2,19 & 14,05 & 35,68 & 30,30 & $37.301,02$ \\
\hline
\end{tabular}

Legenda: 03-Formação Florestal; 09-Floresta Plantada; 12-Formação Campestre; 15-Pastagem; 21-Mosaico de Agricultura e Pastagem; 24-Infraestrutura Urbana; 25-Outra Área não Vegetada; 27-Não observado; 29-Afloramento Rochoso; 30-Mineração; 33-Rio, Lago e Oceano.

Fonte: Elaboração própria.

Figura 12: Variação da área de cada classe de uso da terra, na área de estudo, nos anos de 1987, 1997, 2007 e 2017 no município de Rio Piracicaba

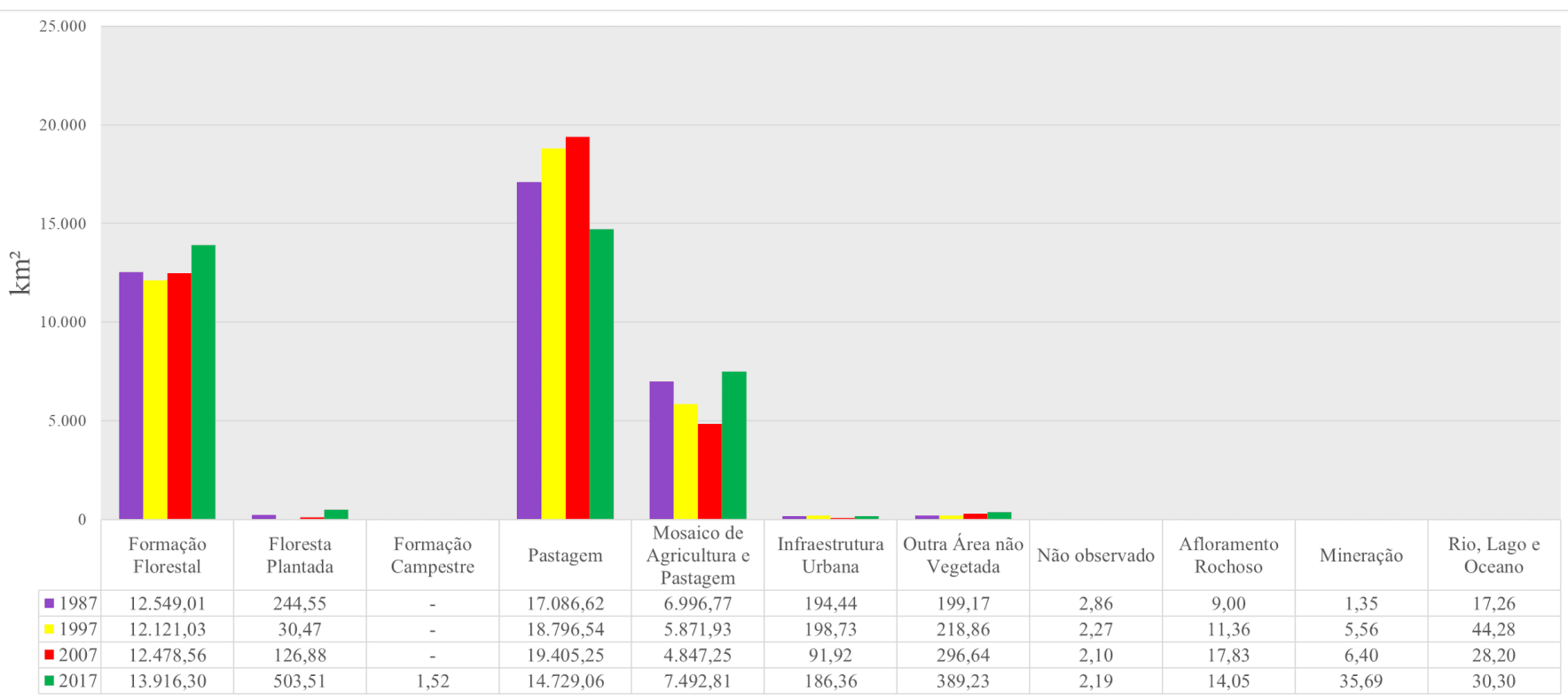

Fonte: Elaboração própria. 
Para o município de Rio Piracicaba, o destaque nas mudanças de uso da terra no período foi o aumento da área de mineração e da floresta plantada, principalmente sobre áreas de pastagem.

\section{CONCLUSÃO}

A partir da análise das mudanças de uso da terra para cada município da microrregião de Itabira com atividade de mineração, nos últimos 30 anos, observou-se que houve poucas mudanças expressivas. As principais mudanças, em geral, foram o crescimento da infraestrutura urbana e de áreas de mineração. Identificou-se também diminuição da floresta nativa (formação florestal) e aumento de áreas com floresta plantada, provavelmente eucalipto. Porém, alguns municípios áreas de pastagens foram substituídas por mata nativa e mosaico de agricultura e pecuária, indicando desenvolvimento e recuperação ambiental.

O aumento expressivo na arrecadação dos municípios nos últimos 20 anos poderá contribuir com novas alterações do uso da terra no futuro. Muitos destes municípios já estão iniciando a diversificação das atividades, com intuito de diminuir a dependência da mineração e aumentar o desenvolvimento socioeconômico.

Assim, estudos futuros serão necessários para essa identificação de crescimento e uso da terra de forma mais intensiva, no sentido do desenvolvimento agropecuário e diversificação da indústria. Essa dinâmica do uso da terra, caso os recursos sejam bem empregados, poderão permitir também o aumento de áreas de reflorestamento do bioma mata atlântica, indicando ser um crescimento sustentável.

\section{REFERÊNCIAS}

BASTOS, ALVARENGA, C. P. A Vulnerabilidade Econômica do Município de Itabira, Minas Gerais, em Relação à Atividade Mineral. Dissertação de Mestrado. UFOP, 2006. $114 \mathrm{p}$.

ANM - Agência Nacional de Mineração. Arrecadação CFEM do Estado: MG (2003 e 2016). Sistema Arrecadação. Site. Disponível em: https://sistemas.anm.gov.br/arrecadacao/extra/relatorios/arrecadacao_cfem_muni.aspx?ano $=2003 \& u f=M G$ e https://sistemas.anm.gov.br/arrecadacao/extra/relatorios/arrecadacao_cfe m_muni.aspx?ano=2016\&uf=MG. Acesso em 19 junho 2020. 
ARAUJO, L. O. S.; MORAIS, C. S. Rigidez locacional e os impactos socioeconômicos e ambientais da Mina de Brucutu no Município de Barão de Cocais - MG. Revista Engenharia de Interesse Social (REIS), UEMG-João Monlevade - MG, v.1, p1-15, 2016.

ARRAES, C. L.; ROCHA, A. M. ; MORAES, R. A.; PISSARA, T. C. T ; RODRIGUES, F. M; ZANATA, M. Estimativa da taxa de desmatamento do Município de Bannach, Pará - Amazônia Legal, utilizando imagens Landsat5/TM. Revista de Ciências Agrárias (Lisboa), v. 32, p. 231-243, 2010.

BRAGA, R. O espaço geográfico: um esforço de definição. GEOUSP: Espaço e Tempo (Online), (22), 65-72. 2007.

MENKE, A. B., \& DE CARVALHO JUNIOR, O. A.; GOMES, R. A. T., MARTINS, E. S.; OLIVEIRA, S. N. Análise das Mudanças do uso agrícola da terra a partir de dados de Sensoriamento Remoto Multitemporal no município de Luís Eduardo Magalhães (BA - Brasil). Sociedade \& Natureza, 21 (3), 315-326, 2009.

DIAS, R. L.; OLIVEIRA, R. C. Caracterização socioeconômica e mapeamento do uso e ocupação da terra do litoral sul do estado de São Paulo. Soc. \& Nat., Uberlândia, 27 (1): $111-123$, jan/abr/2015.

DINIZ, J. M. F. S.; REIS, A. A.; ACERBI JUNIOR, F. W.; GOMIDE, L. R. Detecção da expansão da área minerada no quadrilátero ferrífero, Minas Gerais, no período de 1985 a 2011 através de técnicas de sensoriamento remoto. Bol. Ciênc. Geod., Curitiba , v. 20, n. 3, p. 683-700, Sept. 2014 .

FERNANDES, M. R. M.; MATRICARDI, E. A. T.; ALMEIDA, A. Q.; FERNANDES, M. M. Mudanças de uso e de cobertura da terra na região semiárida de Sergipe. Floresta e Ambiente. 22(4): 472-482. 2015.

FUJACO, M. A. G.; LEITE, M. G. P.; MESSIAS, M. C. T. B. Análise multitemporal das mudanças no uso e ocupação do Parque Estadual do Itacolomi (MG) através de técnicas de geoprocessamento. REM: R. Esc. Minas, Ouro Preto, 63(4): 695-701, out. dez. 2010 .

MAPBIOMAS. Projeto MapBiomas - Coleção 3.1 da Série Anual de Mapas de Cobertura e Uso de Solo do Brasil. Disponível em: http://mapbiomas.org/pages/database/mapbiomas_collection. Acesso em 01 junho 2019.

MARIANO, R. Bela Vista triplica arrecadação mineral em 2014. Hoje em dia, Belo Horizonte,0 17, agosto de 2014. Disponível em: https://www.hojeemdia.com.br/primeiroplano/bela-vista-triplica-arrecada\%C3\%A7\%C3\%A3o-mineral-em-2014-1.271531. Acesso em: 30 maio 2020.

MARTINS, Nildred Stael Fernandes. Dinâmicas Urbanas e Perspectivas de Crescimento - Itabira - MG. Belo Horizonte: UFMG/CEDEPLAR, 2003. 113 p.

MELlO, Ediméia Maria Ribeiro. Mineração de Ferro e Enclave: Estudo de Caso da Companhia Vale do Rio Doce, IX Seminário da Economia Mineira, 2000. 24 p. 
MME - Ministério de Minas e Energia. CFEM: divulgada lista provisória de municípios afetados que podem receber verba. Site. Disponível em: http://www.mme.gov.br/secretarias/geologia-mineracao-e-transformacao-mineral/noticias//asset_publisher/Idc0DUAr9UAE/content/cfem-divulgada-lista-provisoria-de-municipiosafetados-que-podem-receber-verba. Acesso em 19 junho 2020.

MOREIRA, Mauricio A. Fundamentos do Sensoriamento Remoto e Metodologias de Aplicação. $3^{\text {a }}$ ed. Viçosa/MG: UFV, 320p, 2007.

NAHAS, M. M.; SIMÕES, R. F.; GOLGHER, A. B.; RIBEIRO, L. C. S. Especialização e diversificação produtiva: um modelo de painel espacial para a indústria extrativa mineral em Minas Gerais, 2000-2010. v.29, n.1. p.7-40. Belo Horizonte: Nova Economia; 2019. [Internet]. Disponível em: http://www.scielo.br/scielo.php?script=sci_arttext\&pid=S0103$63512019000100007 \& \operatorname{lng}=\mathrm{en} \& n r m=$ iso. Acesso em maio 2020.

QGIS Development Team. QGIS Geographic Information System. Open Source Geospatial Foundation Project. 2020. Disponível em: http://qgis.osgeo.org.

ROSSATO, P. L.; ROSSATO, M. V.; LIMA, J. E. Análise do Desenvolvimento Socioeconômico das Microrregiões de Minas Gerais. DOCUMENTOS TÉCNICOCIENTÍFICOS - Revista Econômica do Nordeste. 40(2). 2009.

SIDRA: Banco de dados agregados do IBGE. Disponível em: http://www.sidra.ibge.gov.br/. Acesso em nov. 2019.

SIQUEIRA, J. Diversificação se torna prioridade para São Gonçalo do Rio Abaixo. Diário do Comércio, Belo Horizonte, 21, novembro de 2019. Disponível em: https://diariodocomercio.com.br/economia/diversificacao-se-torna-prioridade-para-saogoncalo-do-rio-abaixo/. Acesso em: 05 junho 2020. 